Communication

DOI: $10.15436 / 2381-0750.18 .1780$

\title{
The Man and the Cycle of Water in Nature
}

\author{
Khalidullin O.H*, Nurushev M.Zh, Duskaev KK \\ Academician of the Russian Federation LAN, Kazakh National University, Russia
}

*Corresponding author: Khalidullin $\mathrm{OH}$, Ecology Professor, Academician of the Russian Federation LAN, Kazakh National University, Russia, Tel: 87770550099; E-mail: 7115215@mail.ru

\section{Introduction}

It is known that for the period from 2010 to 2016 the frequency of such dangerous phenomena increased by $46 \%$. A total of 797 such events were recorded on the planet in $2016^{[1]}$.

Each fertile hectare of land contains 20 tons of underground animals $\mathbf{s}^{[2]}$, which, together with plants and terrestrial biota, processes water, returning to the atmosphere its "record" in the form of a special structure of exhaled steam, evaporation of precipitates in a moderate enough dose.

The mechanism of the water cycle developed by nature consisted of several main interdependent and unconditional processes:

- concentration of water vapor and movement in the clouds

- Condensation and precipitation in specified locations

- Soil saturation

- Dissolution of mineral microelements, salts, decomposing biomaterials

- movement and transformation of water in food chains

- Evaporation and movement towards the clouds.

Each molecule of this pair has its own, especially individual, structure. And these structures must be very different from the molecules of water evaporated from asphalt or from a drying cup. Billions of years of biologically structured substance, collected in the atmosphere from vapors of organic vapors of living beings and plants, created a clear program of distribution and schedule of precipitation.

We change the water cycle by changing the evaporation. Intensively reduce the element of water movement through the biota and increase the concentration of water vapor in clouds and precipitation, through direct evaporation without performing water on land.

The man took $63 \%$ of its land from the land to arable land, reservoirs, landfills, asphalted areas of cities and roads, and two-thirds of it was destroyed in the XX century ${ }^{[3]}$. We turned the water into a working reagent, forcing it to rotate the turbines, to carry warmth, to wash and dry everything that a person uses from washing hands to evaporating from cooling the reactors of nuclear power plants. Technogenic processes associated with water - pumps, turbines, pipelines, as well as heating, chemical, physical and any other influences - change its natural structure. Volumes of such waters can easily be imagined if we mentally summarize what passes through the turbine blades of hydroelectric power stations of the whole world, all water pipelines. To this, you can add moisture to the air, sucked up by all the engines, compressors and many other mechanisms.

There are many studies that water has a structure, and it varies depending on the impacts on it, for example: Vadim DERUZHINSKY Analytical newspaper "Secret Research", No.
16, 2006 - [4] "Undoubtedly, tap water is ....". It has been experimentally proved that water is also a self-organizing system (Antonov, Gylybova, 1992) $)^{[5]}$. In the circulation of water through the atmosphere and soil, it undergoes a certain cycle of transformation. Changes occurring in the water as a result of external influences are stable in time and change their structure in a given regime.

This means that water "remembers" the physical or chemical effects. The question of the "memory" of water is extremely interesting. The first studies related to "Informativeness" of water were carried out by Deryagin and Churaev (1971). The stability of the results in time after the "activation" of the alternating magnetic field and during electrolysis through the filter-nucleopore was examined by Minenko (1981) and Evseev $(1982)^{[6]}$. Studies of changes in the spectrum of natural water as a function of time have been carried out (Antonov et al., 1995). In modern science, the question of how long information is retained by water molecules is debatable. On the other hand, water has a number of exceptional properties that allow it to store and distribute information as a result of an external physical or chemical impact factor (Dr. Ignatov) $)^{[7]}$.

Based on these studies, it is possible to prolong judgments and assume that such waters carry to the clouds various structures from each individual, living creature, each plant.

As a part of the air, there are always water vapors, they pass through the cylinders of working internal combustion engines, compressors, furnace furnaces, where they are heated by hundreds of degrees, are discharged into the atmosphere with a distorted structure. How many such mechanisms are there in the world? Especially humid is the air in the clouds, through which airliners with turbine and jet engines regularly pass. The same volumes of air burn marine ships whose engines absorb moist air on the surface of the oceans, locomotives of railways around the clock.

\section{Received date: January 23, 2018 \\ Accepted Date: March 29, 2018 \\ Published Date: April 03, 2018}

Citation: Khalidullin O.H. The Man and the Cycle of Water in Nature. (2018) J Marine Biol Aquacult 4(1): 27- 29.

Copy Rights: (C) 2018 Khalidullin O.H. This is an Open access article distributed under the terms of Creative Commons Attribution 4.0 International License. 
In winter time a person develops huge areas for cleaning roads and squares of cities and other surfaces from snow. Sealing snow with wheels and snow removal also breaks the structure of snow crystals. This snow also evaporates, carrying the destroyed structure into the sky.

It is not known what happens to the pairs of waters of the destroyed structure in the clouds, but it is assumed that the change in the substance of the clouds has changed the mechanism of atmospheric phenomena. Appeared the circulation of artificial fumes, growing daily with new technologies, increasing human comfort, increasing the productivity of all types of production. There is no research in this direction. The assumption requires proof, but there is no doubt that artificial evaporation increases with the volumes and speed of turnover between the atmosphere and the soil. The assumption that carbon dioxide has created a greenhouse blanket is not yet known. Why do not water vapor form a thin film in the atmosphere, and carbon dioxide forms such a shell and does not let heat into space or reflects solar radiation. Can it be $\mathrm{CO} 2$, also moved by the wind in the form of invisible clouds and no hotbed over the planet exists? It is known ${ }^{[8]}$ that: "From the beginning of the 20th century, according to UN experts, the increase in $\mathrm{CO} 2$ emissions was from 0.5 to $5 \%$ per year. As a result, over the last hundred years, 400 billion tons of carbon dioxide have been supplied by combustion of fuel to the atmosphere. "Every year people irrevocably take from rivers and lakes about 2000 cubic $\mathrm{km}$. Fresh water, which is about 5\% of the world's rivers flow ${ }^{[9]}$. Annually. All this water through the sewerage and evaporation leaves into the atmosphere without any organic changes. In 1 cubic $\mathrm{m}$. There are 1000x1000x1000 $=1000000000$ or 1 billion cubic meters. Multiply by 2000 and get 2 trillion cubic meters. m. or 2 tr. tons of water. We believe that all this water is in the balance of the circuit. As much it rises into the atmosphere. Therefore 400 billion tons of CO2 in 100 years or 4 billion tons per year is 0.2 percent in the composition of evaporation. It is necessary to add to this even the volumes of natural biota water, it remained $100-63=37 \%$. This percentage is rapidly declining with the development of production. As confirmed by reference data ${ }^{[10]}$ : "The Earth's atmosphere is to a large extent a product of living organisms. The approximate composition of the Earth's atmosphere: $78.08 \%$ nitrogen, $20.95 \%$ oxygen, a variable amount of water vapor (average about 1\%), $0.93 \%$ argon, $0.038 \%$ carbon dioxide, and a small amount of hydrogen, helium, other noble gases and pollutants ". Here it is - "an average of about 1\%" - a long-obsolete figure and needs clarification. According to the carbon dioxide gas, it was calculated and determined: from 0,038 to $0,2 \%$. The same studies on evaporation are required. At the water we took away its most important link, the function - the transformation in the organic. Giant masses of water return to the atmosphere without natural structural transformations. Evaporation of water from asphalt, steam generator, from the kettle and drying dishes is artificial evaporation. They are not provided for by nature. As any change in quantity leads to a new quality, the reduction of one of the links in the water cycle on a global scale has led to natural disasters, the intensity and frequency of which increases every year and leads to the complete destruction of life on the planet. And it, the destruction, has already begun ${ }^{[11]}$ : Scientists state that many species of plants, animals, birds and insects disappear from the face of our planet 1,000 times faster than the natural level. This means that we lose
10 to 130 species every day ${ }^{[12]}$ : The authors calculated the economic damage amounted to seven trillion dollars. The scientists came to their conclusions by analyzing the data on 35 thousand natural disasters that occurred in the last hundred years, which led to the death of more than eight million people. Adaptation to a changing climate can prolong the agony of the planet for a day, a year, even for a decade. The fight against carbon dioxide, the transition to "green technologies", alternative energy sources all these are necessary, but far inadequate measures. It looks like the movement of a leaky boat with passengers bailing out water. A hole in the boat is increasing. It is necessary to understand and accept the closure of the hole - to restore nature the ability of historical self-regulation. The circulation of water in nature should be from organic vapors, but not from artificial ones. The volumes of artificial fumes are huge and grow every day and at a high rate. Compare that it evaporates faster - water from asphalt or from the soil? If you pour over the bucket to and fro. The properties of water have not been studied. Water is not an unraveled matter. There are studies that state that water is not just a working reagent. Every day, floods occur in various parts of the world. It is the reaction of water to the attitude of a person to it in a single chain of transformations. Unprocessed water, repeatedly falling into the shortened circulation - anomalous water, shows its unknown to us new qualities. Gathering in huge clouds, it's ugly with typhoons, cyclones, storms, pouring out massive sediments, overflowing rivers, looking for a job - getting out on the ground, warns us. Creates new atmospheric phenomena, from which the weather and climate is formed. Thus, the true source of anthropogenic impact on the climate is artificial vaporization. Dialectically, the increase in the volume and rate of evaporation has become a new quality: a new atmospheric environment, previously unseen properties. The end Intrusive into droplets, and forming impenetrable cloud layers of increased volumes, block the interchange of energy between space and earth, change the climate according to an unknown algorithm. Urgent studies and evidence of the proposed direction are needed. On their basis, it is proposed to develop a new global concept, strategy and tactics, to rethink the entire population of the planet the nature of the destruction of the natural cycle. To preserve the habitat for our offspring, we must begin now to restore the natural evaporation from plants and animals - the basis of the universe. The main elements of the new concept:

-It is necessary to completely revise the strategy for the development of the electric power industry. A complete ban on the design and construction of new dam power stations with the flooding of riverine areas. Struggling with the emission of carbon dioxide, many governments are designing and building many new hydroelectric power stations. This further increases artificial evaporation. The aging dams of many hydroelectric power stations require reconstruction and repair. Strong water jet strikes against turbine blades destroy the water structure. Studies are required in this direction, which should reveal the influence of such structures on evaporation.

-The existing dam hydroelectric power plants can be gradually converted to damless ones, while maintaining the generation of electricity. There are such interesting designs ${ }^{[13]}$.

-Total saving of water consumption is necessary. Revise all production and utility processes with the transfer of water consumption into closed cycles. For example, why flushing in 
the toilet bowls produces the purest drinking water. Certainly there are opportunities to use waste water here, for example, after washing. - Reconstruction of agriculture, transition to non-plowing, drip irrigation, organic farming. Israel develops deserts, growing vegetables and fruits for export

-Termination of soil contamination by landfills and dumps and reclamation of existing dumps. Creation of non-waste technologies, as in Scandinavian countries

-Reduction of washing of everything that is washed and dried. There are, and need to develop new, methods of dry cleaning of objects and surfaces, for example, cars, cleaning of asphalt pavements and roads. • Outdoor landscaping of buildings and structures. The walls and roofs of buildings and all structures can be covered with vegetation. There are such houses and structures $^{[14]}$. A new direction - vegetation can be vegetable and fruit. That each house can provide its own population with its own product

- Gradual transition to underground and underwater construction, starting from the development of ores, dressing, smelting, obtaining a finished product - all this can be done underground, in the worked out spaces. If it's metals, then the metal is exported to the surface. If it is oil, then only the fuel rises to the surface. If it is uranium, then electricity is output. All types of production must be located underground. And then everything else, down to the dwelling. There are many retail areas and metro in many large cities. There are real projects of underwater and underground cities. For example ${ }^{[15]}$.

There are underground greenhouses, where vegetables and fruits are grown all year round. Based on the materials of The New York Times, the modern rich men of America and Europe are already preparing underground housing and villages with swimming pools, cinemas, gaming halls, hydroponics gardens, trams. Only general mobilization in this direction can restore natural evaporation and the natural circulation of water - the basis of the universe. This is the only way to return a comfortable climate. Of course, all this is not done suddenly, right away. But on a reasonable scale, humanity must gradually come to this. And our duty is to leave our offspring a normal climate, normal weather, to exclude natural disasters. The hypothesis requires proof, research. The officially recognized hypothesis of an increase in carbon dioxide in the greenhouse blanket is also not proven and has become a dogma. The pursuit of $\mathrm{CO} 2$ reduction diverts the world community from the true causes of climate change and leads to the death of all life on the planet. An urgent cooperation of new specialists is needed, which will see the idea and organize a campaign against dogma. Our planet needs salvation ${ }^{[16]}$.

\section{References}

1. https://news.rambler.ru/articles/38301979-klimat-rasshatalsya-dalshe-budet-esche-huzhe/

2. http://smoldacha.ru/osnovy_prirodnogo_zemledeliya.html

3. http://geographyofrussia.com/razrushenie-estestvennyx-ekosistem/

4. http://secret-r.net/arkhiv-publikatsij/6-1998-2006/voda-zhivaja-i-mertvaja

5. http://www.cawater-info.net/all_about_water/?p=1921

6. http://www.nitva.narod.ru/prilojenie/nauka/fizika/ignatov_i_ vodaOsnovaVsego.htm

7. http://www.medicalbiophysics.bg/en/water_memory.html

8. https://www.kazedu.kz/referat/111525/2

9. http://www.erudition.ru/referat/ref/id .48920_1.html

10. http://dic.academic.ru/dic.nsf/ruwiki/6330

11.http://terramia.ru/chelovek-i-priroda/25-vidov-zhivotnyh-nahodyashhihsya-na-grani-vymiraniya/

12. https://lenta.ru/news/2016/04/19/losses/

13. http://www.informograd.narod.ru

14. http://www.novate.ru/blogs/070116/34482/

15. http://gearmix.ru/archives/2174

16. http://ecsocman.hse.ru/data/2010/10/20/1214791094/Fomichev.pdf

Submit your manuscript to Ommega Publishers and we will help you at every step:

- We accept pre-submission inquiries

- Our selector tool helps you to find the most relevant journal

- We provide round the clock customer support

- Convenient online submission

- Thorough peer review

- Inclusion in all major indexing services

- Maximum visibility for your research

Submit your manuscript at

OMMEGA Publishers

https://www.ommegaonline.org/submit-manuscript 